\title{
Effect of Molar Ratios in the Crystallochemical Structure of Biomimetic Nanostructured Hydroxyapatite on the Characteristics of the Product
}

\author{
M. A. Trubitsyn ${ }^{a}$, Hoang Viet Hung ${ }^{a}$, L. V. Furda ${ }^{a}$, and Nguyen Thi Tham Hong ${ }^{b}, c, *$ \\ ${ }^{a}$ Belgorod State Research University, Belgorod, 308015 Russia \\ ${ }^{b}$ Division of Computational Physics, Institute for Computational Science, Ton Duc Thang University, \\ Ho Chi Minh City, 758307 Vietnam \\ ${ }^{c}$ Faculty of Electrical \& Electronics Engineering, Ton Duc Thang University, Ho Chi Minh City, 758307 Vietnam \\ *e-mail: nguyenthithamhong@tdtu.edu.vn
}

Received October 19, 2020; revised December 29, 2020; accepted December 30, 2020

\begin{abstract}
The results of the study of effects of molar ratios in the crystallochemical structure of biomimetic hydroxyapatite (BMHAP) on the physicochemical characteristics of the product are presented. With an increase in molar ratio in the range 1.50-1.67, there is an increase in the unit cell parameters $a$ and $c$, while the average crystallite size increases from 7.52 to $70.30 \mathrm{~nm}$. Particles of all samples in aqueous suspensions ( $\mathrm{pH} 7$ ) are negatively charged. The trend of the zeta potential of the synthesized powders in the range of investigated molar ratios is elucidated. The bioactivity of the samples is evaluated. All BMHAP samples have a higher bioresorbability as compared to unmodified stoichiometric hydroxyapatite, correlating well with the molar ratio in the structure of the products
\end{abstract}

Keywords: synthesis, bioresorbability, silicate ions, carbonate ions

DOI: $10.1134 /$ S0036023621050211

\section{INTRODUCTION}

The development of new synthetic biomaterials intended for the restoration of bone defects is one of the topical areas of medical materials science [1-4]. Materials based on hydroxyapatite $\left(\left[\mathrm{Ca}_{10}\left(\mathrm{PO}_{4}\right)_{6}(\mathrm{OH})_{2}\right]\right.$, HAP) have been successfully used as implants in reconstructive surgery, orthopedics, and dentistry for several years, for they are chemical analogues of human and animal bone tissue bioapatite [5-8]. However, ceramic HAP-based implants have unsatisfactory bioresorbability and poorly induce the formation of new bone tissue, which is a significant drawback [9, 10]. A promising approach to this problem can be the development of biomimetic HAP by chemically modifying it with biocompatible anions in order to purposefully regulate the bioactivity and osteoinduction of the materials.

According to related literature [11-13], biogenic apatite is nanostructured calcium-deficient hydroxyapatite with appropriate cationic $\left(\mathrm{Na}^{+}, \mathrm{Mg}^{2+}, \mathrm{K}^{+}\right.$, $\mathrm{Zn}^{2+}$, and $\left.\mathrm{Sr}^{2+}\right)$ and anionic $\left(\mathrm{F}^{-}, \mathrm{Cl}^{-}, \mathrm{SO}_{4}^{2-}\right.$, and so on) substitutions. The presence of these anions in the HAP structure has a significant effect on a living organism and stimulates the regeneration of fullfledged bone tissue.
Silicate and carbonate ions are most important of the ionic substitutions currently used in the synthesis of HAP [14-20]. Silicate ions $\left(\mathrm{SiO}_{4}^{4-}\right)$ are of particular interest in this regard due to their decisive role in bone tissue restoration, and the incorporation of carbonate ions into the HAP structure improves resorption and increases the osteointegration rate.

It was also reported [21, 22] that the addition of citrate ions $\left(\mathrm{Cit}^{3-}\right)$ into the reaction medium during HAP synthesis changes the structural and morphological characteristics of the product materials. Citrate ions participating in biological cycles play an important role in bone tissue resorption and bioapatite formation, for example, during the nanoscale stabilization of HAP crystallites in bone [23-26].

Thus, in terms of chemical composition, bioapatite is a nanostructured calcium-deficient hydroxyapatite containing silicate and carbonate ions. We have already performed a series of studies into the synthesis of biomimetic calcium-deficient hydroxyapatite (BMHAP) doped with silicate and carbonate ions in the presence of citrate ions [22,27].

Here, we present the results of our study into the effects of molar ratios $C_{\mathrm{Ca}^{2+}} /\left(C_{\mathrm{PO}_{4}^{3-}}+C_{\mathrm{CO}_{3}^{2-}}+C_{\mathrm{SiO}_{4}^{4-}}\right)$ in the crystallochemical structure of BMHAP on the 
physicochemical and biological properties of the products.

\section{EXPERIMENTAL}

The initial reagents used were $\mathrm{Ca}\left(\mathrm{NO}_{3}\right)_{2} \cdot 4 \mathrm{H}_{2} \mathrm{O}$ (pure for analysis grade), $\left(\mathrm{NH}_{4}\right)_{2} \mathrm{HPO}_{4}$ (pure for analysis grade), $\left(\mathrm{C}_{2} \mathrm{H}_{5} \mathrm{O}\right)_{4} \mathrm{Si}$ (TEOS, specialty grade), $\left(\mathrm{NH}_{4}\right)_{2} \mathrm{CO}_{3}$ (pure for analysis grade) and $\mathrm{NH}_{4} \mathrm{OH}$ (analytical reagent grade). The source of citrate ions was a citric acid solution prepared beforehand. BMHAP samples were synthesized by chemical precipitation from aqueous solution at $22 \pm 2{ }^{\circ} \mathrm{C}$ and $\mathrm{pH} 10 \pm 0.5$ by a known procedure [27]. Citrate ions $\mathrm{Cit}^{3-}$ were added in an amount of $0.46 \mathrm{wt} \%$ for regulating nucleation and HAP crystal growth. The BMHAP precipitation reaction proceeded according to the equation

$$
\begin{aligned}
& (10-d) \mathrm{Ca}\left(\mathrm{NO}_{3}\right)_{2}+(6-x-y)\left(\mathrm{NH}_{4}\right)_{2} \mathrm{HPO}_{4} \\
& +x\left(\mathrm{NH}_{4}\right)_{2} \mathrm{CO}_{3}+y\left(\mathrm{C}_{2} \mathrm{H}_{5} \mathrm{O}_{4}\right)_{4} \mathrm{Si} \\
\rightarrow & \mathrm{Ca}_{10-d}\left(\mathrm{PO}_{4}\right)_{6-x-y}\left(\mathrm{CO}_{3}\right)_{x}\left(\mathrm{SiO}_{4}\right)_{y}(\mathrm{OH})_{2+x-y-2 d} \\
& \cdot n \mathrm{H}_{2} \mathrm{O}+(20-2 d) \mathrm{NH}_{4} \mathrm{NO}_{3}+4 y \mathrm{C}_{2} \mathrm{H}_{5} \mathrm{OH},
\end{aligned}
$$

where $d$ is the deviation of the molar content of $\mathrm{Ca}^{2+}$ in the HAP crystal structure from the stoichiometric value; $d=1,0.7$, or $0.4 ; x$ is the degree of substitution of phosphate ions by carbonate ions; and $y$ is the degree of substitution of phosphate ions by silicate ions.

The thus-prepared suspension was allowed to stand for $24 \mathrm{~h}$ at room temperature to complete phase formation, then the solid was filtered from the mother solution, thoroughly washed with distilled water, and dried to constant weight at $110 \pm 5^{\circ} \mathrm{C}$.

The subjects chosen to be characterized further were BMHAP samples where the molar ratios were $C_{\mathrm{Ca}^{2+}} /\left(C_{\mathrm{PO}_{4}^{3-}}+C_{\mathrm{CO}_{3}^{2-}}+C_{\mathrm{SiO}_{4}^{4-}}\right)=1.50,1.55$, and 1.60 , and where the degrees of substitution of phosphate ions by carbonate and silicate ions in all cases were constant and $x=y=1$. Thus, in terms of chemical composition, all samples were calcium-deficient. The samples were denoted as BMHAP1.50, BMHAP1.55, and BMHAP1.60, respectively. The reference to compare with was unmodified stoichiometric HAP with $\mathrm{Ca} / \mathrm{P}=1.67(\mathrm{~mol} / \mathrm{mol})$ synthesized in the absence of silicate and carbonate ions, but in the presence of citrate ions according to the equation

$$
\begin{aligned}
& 10 \mathrm{Ca}\left(\mathrm{NO}_{3}\right)_{2}+6\left(\mathrm{NH}_{4}\right)_{2} \mathrm{HPO}_{4}+8 \mathrm{NH}_{4} \mathrm{OH} \\
& \rightarrow \mathrm{Ca}_{10}\left(\mathrm{PO}_{4}\right)_{6}(\mathrm{OH})_{2}+20 \mathrm{NH}_{4} \mathrm{NO}_{3}+6 \mathrm{H}_{2} \mathrm{O} .
\end{aligned}
$$

Physicochemical and biological studies of the synthesized samples were carried out using a set of methods. The phase composition was studied on a RigakuSmartLab diffractometer. The accelerating voltage was $40 \mathrm{kV}$, the X-ray tube current was $250 \mathrm{~mA}, 2 \theta=$ $20^{\circ}-70^{\circ}$ with $0.02^{\circ}$ steps, and recording rate was
$3 \mathrm{deg} / \mathrm{min}$. Compounds in the tested samples were identified in the PDXL Qualitative Analysis program using the PDF 2008 database. The crystallite size $D$ and crystallinity $X_{s}$ in the samples were determined by a routine procedure $[28,29]$. IR absorption spectra were recorded on an IRPrestige-21 (Shimadzu) FTIR spectrometer in the wavenumber range from 400 to $4000 \mathrm{~cm}^{-1}$. The morphology and particle sizes in the form of aqueous dispersions and in the form of dried BMHAP powders were determined by digitizing micrographs obtained using transmission (TEM) and scanning (SEM) electron microscopy on JEM-2100 (JEOL) and Quanta-200 3D (FEI), respectively. The images were digitized using the ImageJ software. Specific surface areas $S_{\mathrm{sp}}$ were determined by the BET method on TriStar II 3020 (Micromeritics), a fully automated surface area and porosity analyzer. The surface charge magnitude and sign of the synthesized samples were evaluated by measuring the electrokinetic potential. $\zeta$-Potentials were measured on a Zetasizer Nano ZS (Malvern Instruments) serial analyzer. The bioresorbability of the synthesized BMHAP samples in physiological saline $(\omega(\mathrm{NaCl})=0.9 \%)$ and in model SBF solution ( $\mathrm{pH}$ 7.4) were evaluated as the overall $\mathrm{Ca}^{2+}$ concentration in the solution by complexometric titration after a certain exposure time [30].

\section{RESULTS AND DISCUSSION}

The X-ray powder diffraction phase study of the synthesized samples showed that all BMHAP samples having the molar ratios in the range $1.50-1.60$ are single phases and are nanocrystalline (Fig. 1a), and can be attributed to the hexagonal crystal system (they $\mathrm{P6}_{3} / \mathrm{m}$ ) and identified as modified HAP (ICDD No. 01-072-1243).

Noteworthy, the diffraction patterns of BMHAP powders are distinguished by wider lines and lower intensities compared to unmodified stoichiometric HAP1.67 (Fig. 1b). The observed reduction in intensity of the characteristic peaks in the synthesized BMHAP samples is apparently associated with the incorporation of silicate and carbonate ions into the HAP crystallochemical structure. Thus, the measured $\mathrm{X}$-ray diffraction patterns are identical to those of a typical HAP.

Crystallochemical and textural characteristics of powdered HAP and BMHAP appear in Table 1.

As one can see from Table 1, an increase in molar ratio in the HAP crystal structure in the range 1.501.67 causes a monotonic increase in parameter $c$. For parameter $a$, this trend was not observed. The highest value of parameter $a(0.9523 \mathrm{~nm})$ is in BMHAP1.55. As the molar ratio increases further, parameter $a$ begins to decrease to reach a minimum $(0.9422 \mathrm{~nm})$ in HAP1.67. The unit cell volume changes in the same way as parameters $a$ and $c$. However, we did not elucidated any definite trends in the unit cell parameters of 

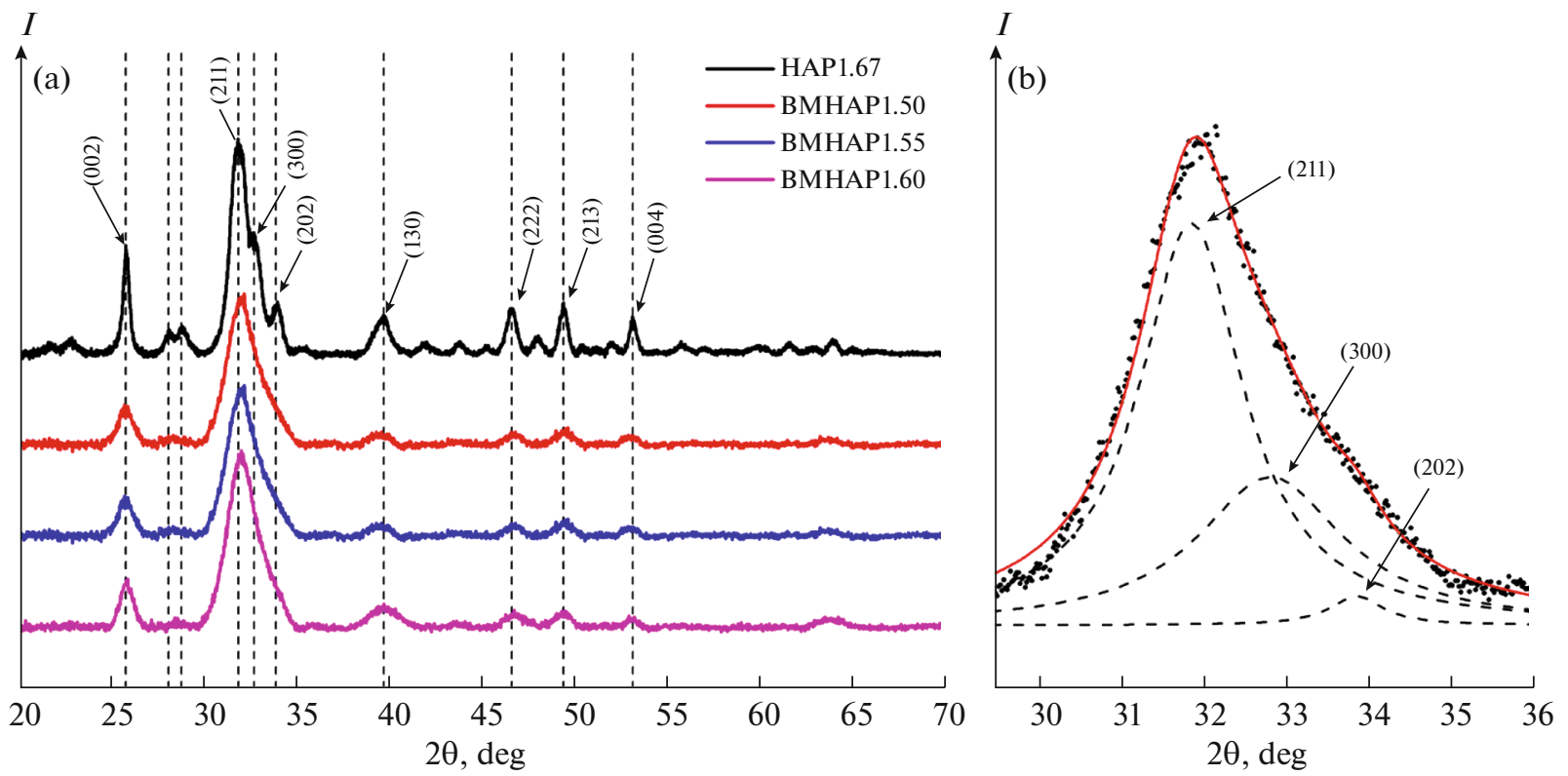

Fig. 1. X-ray diffraction patterns of synthesized samples: (a) general view and (b) diffraction peak (211) and its fit by three Lorentzian functions.

BMHAP depending on the molar ratio. Apparently, this issue requires separate research.

With a decrease in $\mathrm{Ca}^{2+}$ deficiency in the molar ratio range $1.50-1.60$, the crystallite size increases from 7.52 to $11.52 \mathrm{~nm}$. As the molar ratio approaches the stoichiometric value, the crystallite size changes in jump to reach a peak $(70.30 \mathrm{~nm})$ in HAP1.67.

The results of BET specific surface area measurements of the synthesized powders showed that all the studied BMHAP samples have highly developed surfaces compared to unmodified stoichiometric HAP1.67. The peak value of specific surface area $\left(193.53 \mathrm{~m}^{2} / \mathrm{g}\right)$ was in BMHAP1.55. The specific surface areas of the synthesized samples were found to decrease in response to the molar ratio increasing to the stoichiometric value, to reach a minimum $\left(74.41 \mathrm{~m}^{2} / \mathrm{g}\right)$ in HAP1.67.

The FTIR spectra of all BMHAP powders doped with silicate and carbonate ions in the range of specified molar ratios feature absorption bands of $\mathrm{PO}_{4}^{3-}$,
$\mathrm{CO}_{3}^{2-}$, and $\mathrm{OH}^{-}$groups, characteristic of the apatite phase.

The FTIR spectra (Fig. 2) of all HAP1.67 and BMHAP samples feature absorption bands at wavenumbers in the range $607-565 \mathrm{~cm}^{-1}$, corresponding to the bending vibrations of phosphate groups (mode $v_{4}$ ). Bands in the range $1092-1034 \mathrm{~cm}^{-1}$ can be assigned to the asymmetric stretching vibrations of $\mathrm{P}-\mathrm{O}$ bonds in the $\mathrm{PO}_{4}^{3-}$ tetrahedra (mode $\mathrm{v}_{3}$ ), and bands in the range $962-959 \mathrm{~cm}^{-1}$ are caused by the symmetric stretching modes $v_{1}$. The absorption band at $470 \mathrm{~cm}^{-1}$ corresponds to the $\mathrm{O}-\mathrm{P}-\mathrm{O}$ bending vibrations $\left(\operatorname{mode} \mathrm{v}_{2}\right.$ ). The broad band in the range from 3700 to $2500 \mathrm{~cm}^{-1}$ can be assigned to the stretching vibration modes of adsorbate water and hydroxide groups. In addition, bands of $\mathrm{O}-\mathrm{H}$ bending vibrations in structurally bound water molecules and in hydroxide ions appear in the range $1603-1635 \mathrm{~cm}^{-1}$. Presumably, the shift of the bending vibration band of water to $1600 \mathrm{~cm}^{-1}$, as

Table 1. Unit cell parameters, crystallite sizes, and specific surface areas of HAP1.67 and BMHAP samples

\begin{tabular}{l|c|c|c|c|c|c}
\hline \multicolumn{1}{c|}{ Sample } & $a=b, \mathrm{~nm}$ & $c, \mathrm{~nm}$ & $V_{\text {hex }}, \mathrm{nm}^{3}$ & $D, \mathrm{~nm}$ & $X_{s}, \%$ & $S_{\text {sp }}, \mathrm{m}^{2} / \mathrm{g}$ \\
\hline BMHAP1.50 & $0.942(8)$ & $0.685(4)$ & $0.527(6)$ & $7.52(0)$ & 88.18 & 192.51 \\
BMHAP1.55 & $0.952(3)$ & $0.685(1)$ & $0.538(0)$ & $8.22(7)$ & 90.28 & 193.53 \\
BMHAP1.60 & $0.948(8)$ & $0.687(4)$ & $0.535(9)$ & $11.52(3)$ & 89.15 & 184.45 \\
HAP1.67 & $0.942(2)$ & $0.687(6)$ & $0.528(6)$ & $70.30(5)$ & 93.93 & 74.41 \\
$\mathrm{Ca}_{10}\left(\mathrm{PO}_{4}\right)_{6}(\mathrm{OH})_{2}(01-072-1243)$ & $0.943(2)$ & $0.688(1)$ & $0.530(1)$ & - & & - \\
\hline
\end{tabular}

$V_{\text {hex }}$ is unit cell volume; $D$ is crystallite size; $X_{s}$ is crystallinity; $S_{\text {sp }}$ is specific surface area. 


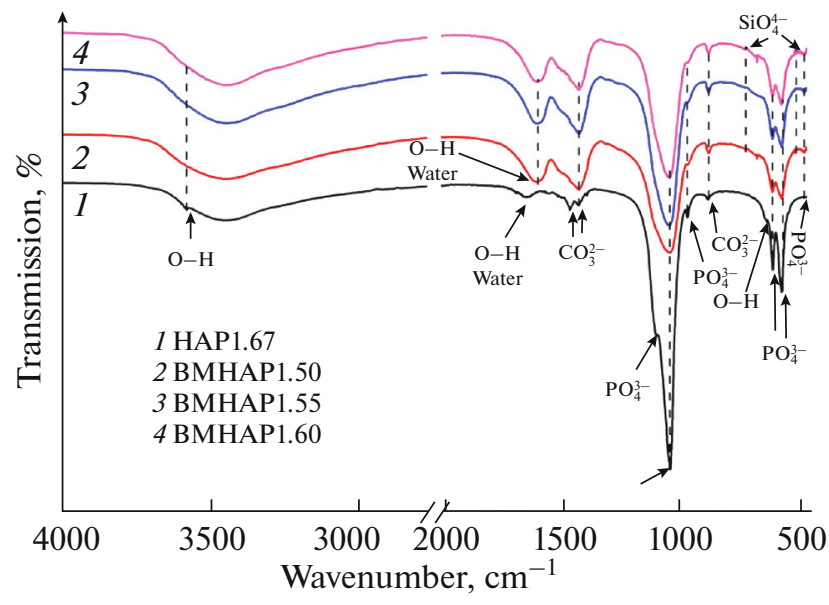

Fig. 2. IR spectra of synthesized HAP1.67 and BMHAP samples.

well as a significant increase in its intensity, can be associated with an increase in the carbonate ion concentration in the HAP structure. The $630 \mathrm{~cm}^{-1}$ band in the HAP spectrum can be assigned to the libration vibrations of $\mathrm{OH}$ groups. Figure 2 shows that the incorporation of both silicate and carbonate ions into the HAP structure leads to the disappearance of this band. After [31, 32], one OH group can be lost for providing charge compensation in the HAP unit cell when $\mathrm{PO}_{4}^{3-}$ is substituted by $\mathrm{SiO}_{4}^{4-}$. When HAP is doped with $\mathrm{CO}_{3}^{2-}$ ions, one $\mathrm{OH}$ group can be lost due to B-type carbonate substitution.

Unmodified stoichiometric HAP1.67 features peaks corresponding to the peak vibrational intensity of $\mathrm{PO}_{4}^{3-}$ groups at 1092 and $602 \mathrm{~cm}^{-1}$, but there are no absorption bands characteristic of silicate groups. In BMHAP samples, the phosphate group vibrations are reduced in intensity due to a partial substitution of phosphate ions by silicate and carbonate ions. The spectra of all samples also feature bands in the ranges 873-871 $\mathrm{cm}^{-1}\left(\operatorname{mode} v_{2}\right)$ and $1456-1417 \mathrm{~cm}^{-1}\left(\operatorname{mode} v_{3}\right)$, respectively, related to the bending and stretching $\mathrm{C}=\mathrm{O}$ vibrations in the carbonate ion. In unmodified stoichiometric HAP1.67, this may be due to the adsorption of carbon dioxide from the air during the synthesis. The BMHAP samples feature broadening and an increase in intensity of the band peaking at $1417 \mathrm{~cm}^{-1}$, which corresponds to $\mathrm{CO}_{3}^{2-}$ vibrations (mode $v_{3}$ ). In our opinion, this is due to the superposition of the $1417 \mathrm{~cm}^{-1}$ absorption band and the $1458 \mathrm{~cm}^{-1}$ band, which occurs due to the incorporation of carbonate ions into the HAP structure. In contrast to the FTIR spectrum of stoichiometric HAP1.67, the spectra of silicate- and carbonate-doped BMHAP powders exhibit characteristic low-intensity absorption bands due to the bending vibrations of $\mathrm{Si}-\mathrm{O}$ bonds and the symmetric stretching vibrations of $\mathrm{Si}-\mathrm{O}-\mathrm{Si}$ bridging bonds in silicate tetrahedra at $504 \mathrm{~cm}^{-1}\left(\operatorname{mode} v_{2}\right)$ and $\sim 720 \mathrm{~cm}^{-1}$ (mode $v_{1}$ ), respectively. The appearance of these bands [31, 33] signifies that silicate ions have been incorporated into the HAP lattice.

Morphological study of as-synthesized HAP1.67 and BMHAP samples in the form of aqueous dispersions was carried out by TEM. Figure 3 shows the TEM images of samples HAP1.67 and BMHAP1.50.

As probed by TEM (Fig. 3), silicate and carbonate ions doped into the HAP structure change the shape and average particle size. Unmodified HAP1.67 has acicular particles $45-100 \mathrm{~nm}$ long and $12-25 \mathrm{~nm}$ wide (Fig. 3a). BMHAP1.50 samples are distinguished by spherical particles with sizes in the range from 13 to $32 \mathrm{~nm}$ (Fig. 3b). Laquerriere et al. [34] wrote that the spherical shape of HAP particles is an important factor in initiating the pro-inflammatory response, and the needle-like shape of the HAP crystals is the least biocompatible one. Lebre et al. [35] reported that the
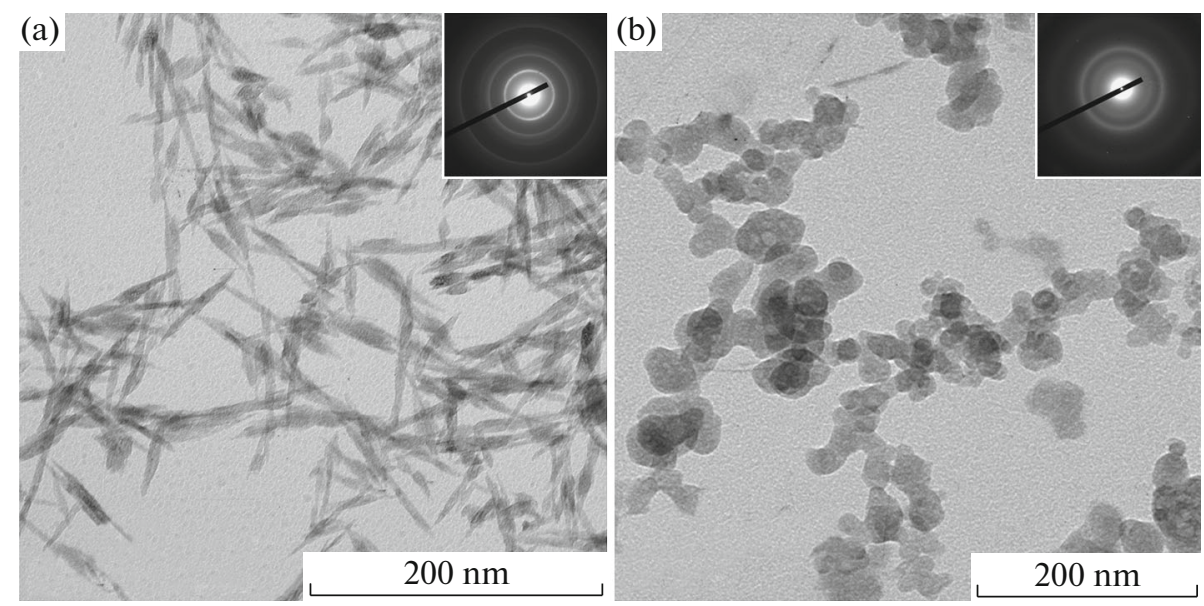

Fig. 3. TEM micrographs of (a) HAP1.67 and (b) BMHAP1.50 samples. 

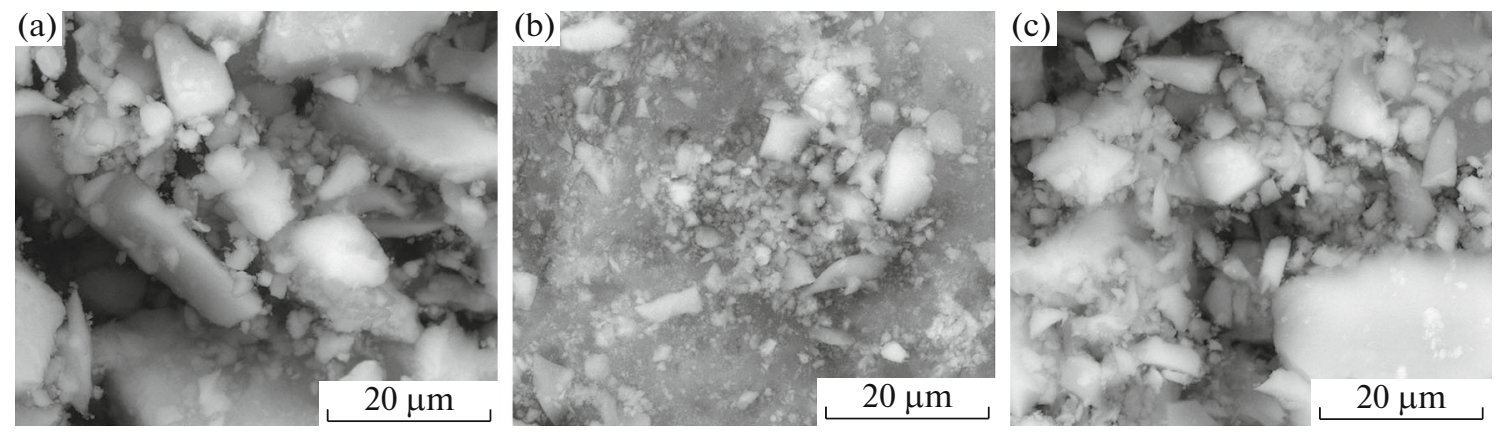

Fig. 4. SEM micrographs of (a) HAP1.67, (b) BMHAP1.50, and (c) BMHAP1.60 samples.

acicular shape of HAP crystals with micrometer-sized particles $(0.1$ to $20 \mu \mathrm{m})$ initiates the activation of inflamasome NLRP3 and pronounced IL-1 $\beta$ secretion by macrophages and dendritic bone marrow cells in mice in vitro. At the same time, the inflammatory response did not develop after the intraperitoneal injection of micro- or submicron-sized HAP when the injected HAP particles had a comparable size, but a smooth spherical shape.

An additional structural and morphological study of powdery HAP and BMHAP was carried out by scanning electron microscopy after aqueous dispersions were dried. After the hydrogel was dried to constant weight and then ground in a porcelain mortar, the final synthesis products were fine white powders. Figure 4 shows the SEM micrographs of as-dried materials.

An inspection of the SEM images of HAP and BMHAP samples confirmed that these powdered substances are polydisperse crystalline systems that have a similar morphology and consist of nanoparticle agglomerates with sizes of 2 to $23.5 \mu \mathrm{m}$ for unmodified HAP1.67 and of 1 to $10 \mu \mathrm{m}$ for BMHAPSEM. The micrographs in Fig. 4 show agglomerated microparticles of the dried and pulverized product and not nanosized BMHAP particles dispersed in a liquid as in Fig. 3. HAP crystals lose their hydrate shells while dried, and are aggregated.

In addition to biocompatibility, bioactivity, and osteoinduction, the electrical surface properties of the synthesis products are extremely important for calcium phosphate materials that are used as substrates for the manufacture of bone implants, including BMHAP. It is known that, when a biomaterial is placed inside the body, a biological response immediately occurs at a depth of several nanometers from the surface. At the same time, the surface charge at the interface between the biomaterial and the biological environment has a significant effect on protein adsorption and cell adhesion. Preferential adsorption of calcium cations occurs on negatively charged calcium phosphate materials to form an apatite layer, which enhances the anchorage of proteins and cells to the surface. From this point of view, HAP particles bearing a controlled negative surface charge have a noticeable advantage. The $\zeta$-potentials of the synthesized HAP and BMHAP samples are shown in Fig. 5.

According to the results of dynamic light scattering measurements of $\xi$-potentials (Fig. 5), the particles of all samples have negative charges in aqueous suspension at $\mathrm{pH}$ 7. The $\zeta$-potential experiences a systematic decrease in magnitude (from 4.29 to $1.05 \mathrm{mV}$ ) as the molar ratio in the HAP structure increases in the range 1.50-1.67. So, BMHAP1.50, which has the greatest $\mathrm{Ca}^{2+}$ deficiency, has the greatest negative value of the $\zeta$-potential $(4.29 \mathrm{mV})$; as the molar ratio approaches the stoichiometric value, the $\xi$-potential decreases to reach a minimum in HAP1.67. Thus, for the synthesized BMHAP samples, there is a wide range of variation in magnitude of the negative surface charge, which makes it possible to control their adhesion properties with respect to cells and proteins.

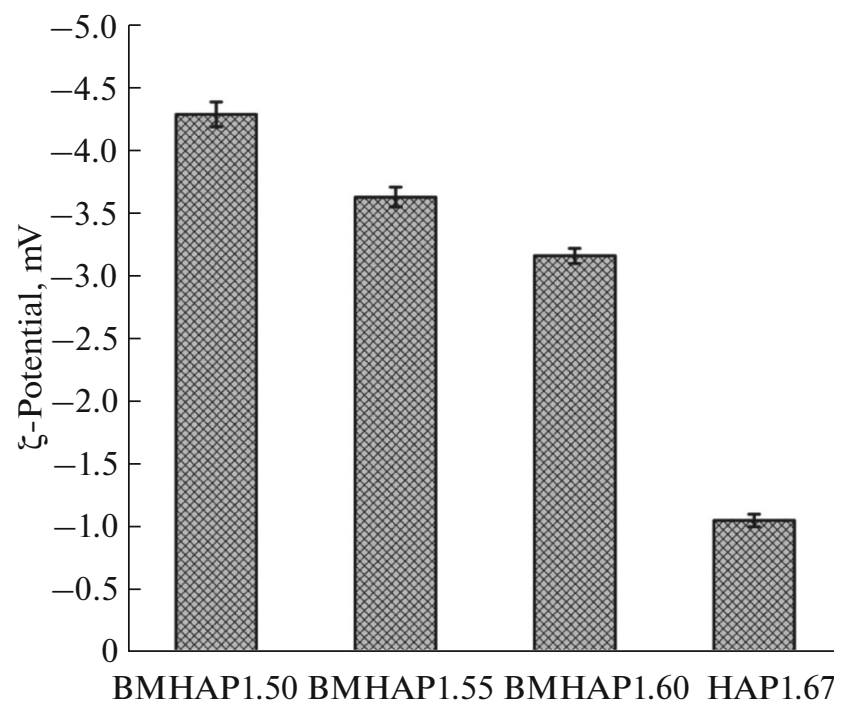

Fig. 5. $\zeta$-Potentials of synthesized HAP1.67 and BMHAP samples. 
Table 2. Solubility of HAP1.67 and BMHAP powders in physiological saline $(\omega(\mathrm{NaCl})=0.9 \%)$

\begin{tabular}{c|c|c|c|c}
\hline \multirow{2}{*}{ Temperature, ${ }^{\circ} \mathrm{C}$} & \multicolumn{4}{|c}{$\mathrm{Ca}^{2+}$ concentration, mmol/L* } \\
\cline { 2 - 5 } & BMHAP1.50 & BMHAP1.55 & BMHAP1.60 & HAP1.67 \\
\hline 22 & 4.10 & 3.75 & 3.60 & 1.10 \\
37 & 4.60 & 4.00 & 3.90 & 2.05 \\
\hline
\end{tabular}

*Average of three determinations.

One more important characteristic of medical calcium phosphate materials is resorbability. After Hendi [8], in accordance with the division of the resorption process into two (slow and fast) phases, which differ from each other in $\mathrm{pH}$ in the resorption zone and the involvement of cells in the process, the study of the solubility of a biomaterial in water or model media can serve as the basis to assess the bioresorbability of the material. In hydroxyapatite biomaterials, bioresorbability depends on several factors, such as the phase composition, crystal size, specific surface area, including the molar ratio in the HAP structure. In this work, the bioresorbability of the synthesized samples was assessed by their bioresorptive capacity, i.e., the intensity of dissolution in physiological saline $(\omega(\mathrm{NaCl})=0.9 \%)$, which is isotonic to human blood plasma, and in SBF solution, which simulates the interstitial body fluid.

The results of solubility determination in HAP1.67 and BMHAP samples in the range 1.50-1.67 (mol/mol) in physiological saline at room temperature $\left(22^{\circ} \mathrm{C}\right)$ and at the human body temperature $\left(37^{\circ} \mathrm{C}\right)$ with 7-day exposure appear in Table 2.

From the data in Table 2, one can see that BMHAP samples have improved bioresorption compared to unmodified stoichiometric HAP1.67. This behavior is in good agreement with Safronova and Putlyaev's data

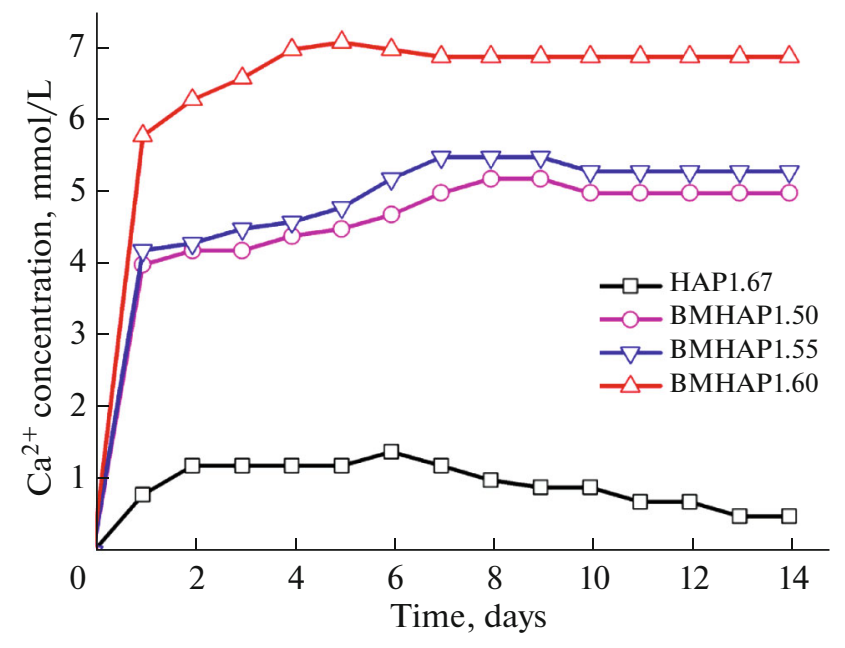

Fig. 6. Release of calcium ions to SBF solution versus exposure time.
[10], according to which the solubility increases when substituent anions have a lower charge and/or a larger radius with a higher hydration energy. For the studied BMHAP samples, the substitution of phosphate ions by silicate and carbonate ions leads to a distortion of the crystal lattice and creates stresses and instability in the HAP structure, which is just responsible for an increased solubility of the material. The solubility in BMHAP samples tends to decrease as the molar ratio increases. So, BMHAP1.50 has a maximum concentration $(4.10 \mathrm{mmol} / \mathrm{L})$ of $\mathrm{Ca}^{2+}$ ions that pass into the liquid phase when the solid is brought into contact with physiological saline. The minimum $\mathrm{Ca}^{2+}$ concentration $(1.10 \mathrm{mmol} / \mathrm{L})$ at the set exposure time was observed for stoichiometric HAP1.67. Thus, after the samples were exposed for 7 days in $0.9 \% \mathrm{NaCl}$ saline, the $\mathrm{Ca}^{2+}$ concentration in BMHAP samples was 1.92.4 times higher than that in unmodified stoichiometric HAP1.67. In addition, an increase in solubility in response to the temperature increasing from 22 to $37^{\circ} \mathrm{C}$ is also noted for all synthesized HAP and BMHAP samples (Table 2).

In order to assess the in vitro biological activity of the synthesized HAP and BMHAP samples, the samples were kept in a model SBF solution (pH 7.4) at a constant temperature of $37 \pm 0.5^{\circ} \mathrm{C}$ for 14 days. At the end of the exposure of the samples in the saturated SBF solution, their bioresorbability was assessed as the quantitative release of $\mathrm{Ca}^{2+}$. The results are shown in Fig. 6.

Figure 6 implies that the dissolution curves in SBF solution have similar trends for all studied samples. The release of $\mathrm{Ca}^{2+}$ ions from HAP1.67 and BMHAP into the SBF solution increases rapidly during the first day to reach the maximum equilibrium value $C\left(\mathrm{Ca}^{2+}\right)$ in 5-7 days. After this period of time, the amount of $\mathrm{Ca}^{2+}$ ions released into the liquid phase decreases slightly, and then remains at a constant level. This fact, apparently, is associated with the formation of a poorly soluble apatite layer on the BMHAP surface, which complicates its further dissolution; as a consequence, there is a slight decrease in $\mathrm{Ca}^{2+}$ concentration in the solution. It is known that $\mathrm{Ca}^{2+}, \mathrm{PO}_{4}^{3-}, \mathrm{SiO}_{4}^{4-}$, and $\mathrm{OH}^{-}$ ions released from calcium phosphate materials like BMHAP play an important role in the formation of a new apatite phase in biological media. 
All BMHAP samples have higher bioresorbability compared to unmodified HAP1.67. From the analysis of the kinetic curves, it follows that BMHAP bioresorbability systematically decreases as the molar ratio increases in the range 1.50-1.67. The highest release of $\mathrm{Ca}^{2+}$ ions into the SBF solution is observed for the BMHAP1.50 sample, and the least is for the stoichiometric sample HAP1.67.

\section{CONCLUSIONS}

Nanostructured biomimetic hydroxyapatite samples have been synthesized by chemical precipitation from aqueous solutions. While the molar ratio increases in the range $1.50-1.67$, unit cell parameters $a$ and $c$ change, the average crystallite size increases from 7.52 to $70.30 \mathrm{~nm}$, and the specific surface area decreases. In aqueous suspensions ( $\mathrm{pH} 7$ ), suspension particles and particles of all samples bear negative charges. The trend has been elucidated in which the $\zeta$-potential of the powder changes in the studied range of molar ratios.

Bioactivity studies by dynamic dissolution in $0.9 \%$ $\mathrm{NaCl}$ saline and in the SBF solution have shown that the resorption rates of HAP1.67 and BMHAP decrease as the molar ratio increases in the crystallochemical structure of the sample.

\section{ACKNOWLEDGMENTS}

Research facilities of the "Technologies and Materials" of the Belgorod State University Share Facilities Center were used in the study.

\section{CONFLICT OF INTEREST}

The authors declare that they have no conflict of interest.

\section{REFERENCES}

1. G. Liangzhi, Z. Weibin, and S. Yuhui, RSC Adv. 6, 114707 (2016). https://doi.org/10.1039/C6RA24469F

2. M. Trunec and Z. Chlup, Ceram. Int. 43, 11265 (2017). https://doi.org/10.1016/j.ceramint.2017.05.177

3. D. S. Larionov, M. A. Kuzina, P. V. Evdokimov, et al., Zh. Neorg. Khim. 65, 309 (2020).

https://doi.org/10.31857/S0044457X20030071

4. O. A. Golovanova, Zh. Neorg. Khim. 65, 302 (2020). https://doi.org/10.31857/S0044457X20030046

5. J. Kolmas, S. Krukowski, A. Laskus, et al., Ceram. Int. 42, 2472 (2016). https://doi.org/10.1016/j.ceramint.2015.10.048

6. A. Szczes, L. Holysz, and E. Chibowski, Adv. Coll. Interf. Sci. 249, 321 (2017).

https://doi.org/10.1016/j.cis.2017.04.007

7. N. Eliaz and N. Metoki, Materials 10, 334 (2017). https://doi.org/10.3390/ma10040334
8. A. A. Hendi, J. Alloys Compd. 712, 147 (2017). https://doi.org/10.1016/j.jallcom.2017.04.021

9. M. Vallet-Regí and D. Arcos, J. Mater. Chem. 15, 1509 (2005).

https://doi.org/10.1039/B414143A

10. T. V. Safronova and V. I. Putlyaev, Nanosist.: Fiz., Khim., Mat. 4, 24 (2013).

11. Nanoscience \& Nanotechnology Series, Chapter 1: Biological Apatites in Bone and Teeth (Roy. Soc. of Chem. Cambridge, 2008), p. 1.

https://doi.org/10.1039/9781847558923-00001

12. Nanoscience \& Nanotechnology Series, Chapter 3: Biomimetic Nanoapatites on Bioceramics (Roy. Soc. of Chem. Cambridge, 2008), p. 61. https://doi.org/10.1039/9781847558923-00061

13. A. J. Salinas, P. Esbrit, and M. Vallet-Regí, Biomater. Sci. 1, 40 (2013). https://doi.org/10.1039/C2BM00071G

14. K. Guth, C. Campion, T. Buckland, et al., Adv. Eng. Mater. 12, B113 (2010). https://doi.org/10.1002/adem.200980026

15. K. Cameron, P. Travers, C. Chander, et al., J. Biomed. Mater. Res. A 101, 13 (2013).

https://doi.org/10.1002/jbm.a.34261

16. V. Putlayev, A. Veresov, M. Pulkin, et al., Mat.-wiss. Werkstofftech. 37, 416 (2006). https://doi.org/10.1002/mawe.200600007

17. G. Munir, G. Koller, L. Di Silvio, et al., J. R. Soc. Interface 8, 678 (2011). https://doi.org/10.1098/rsif.2010.0548

18. E. Landi, G. Celotti, G. Logroscino, et al., J. Eur. Ceram. Soc. 23, 2931 (2003). https://doi.org/10.1016/S0955-2219(03)00304-2

19. E. Landi, J. Uggeri, S. Sprio, et al., J. Biomed. Mater. Res. A 94, 59 (2010). https://doi.org/10.1002/jbm.a.32671

20. E. Boanini, M. Gazzano, and A. Bigi, Acta Biomater. 6, $1882(2010)$. https://doi.org/10.1016/j.actbio.2009.12.041

21. M. Yu. Koroleva, E. Yu. Karakatenko, and E. V. Yurtov, Kolloid. Zh. 82, 324 (2020). https://doi.org/10.31857/S0023291220030052

22. M. A. Trubitsyn, Khoang V'et Khung, and L. V. Furda, Vest. Tekhnol. Univ. 23, 19 (2020).

23. Y.-J. Wu, Y.-H. Tseng, and J. C. C. Chan, Cryst. Growth Des. 10, 4240 (2010). https://doi.org/10.1021/cg100859m

24. Y.-Y. Hu, A. Rawal, and K. Schmidt-Rohr, Proc. Nat. Acad. Sci. 107, 22425 (2010). https://doi.org/10.1073/pnas.1009219107

25. N. R. Jana, L. Gearheart, and C. J. Murphy, J. Phys. Chem. B 105, 4065 (2001). https://doi.org/10.1021/jp0107964

26. V. H. Hoang, M. A. Troubitsin, L. V. Furda, et al., JBBBE 47, 1 (2020). www.scientific.net/JBBBE.47.1

27. M. Troubitsin, V. H. Hoang, and L. Furda, Bull. Belgorod State Technol. Univ. 5, 106 (2020). https://doi.org/10.34031/2071-7318-2020-5-3-106-113 
28. B. D. Cullity and J. W. Weymouth, Am. J. Phys. 25, 394 (1957)

https://doi.org/10.1119/1.1934486

29. G. Singh, S. Singh, and S. Prakash, Surf. Coat. Technol. 205, 4814 (2011).

https://doi.org/10.1016/j.surfcoat.2011.04.064

30. G. Charlot, Les Methods de la Chimie Analytique: Analyse Quantitative Minerale (Masson, Paris, 1966; Moscow, 1966).

31. D. Marchat, M. Zymelka, C. Coelho, et al., Acta Biomaterialia 9, 6992 (2013).

https://doi.org/10.1016/j.actbio.2013.03.011
32. N. Y. Mostafa, H. M. Hassan, and O. H. Abd Elkader, J. Am. Ceram. Soc. 94, 1584 (2011). https://doi.org/10.1111/j.1551-2916.2010.04282.X

33. M. Palard, E. Champion, and S. Foucaud, J. Solid State Chem. 181, 1950 (2008). https://doi.org/10.1016/j.jssc.2008.04.027

34. P. Laquerriere, A. Grandjean-Laquerriere, S. AddadiRebbah, et al., Biomaterials 25, 2515 (2004). https://doi.org/10.1016/j.biomaterials.2003.09.034

35. F. Lebre, R. Sridharan, M. J. Sawkins, et al., Sci. Rep. 7, 2922 (2017).

https://doi.org/10.1038/s41598-017-03086-0

Translated by $O$. Fedorova 